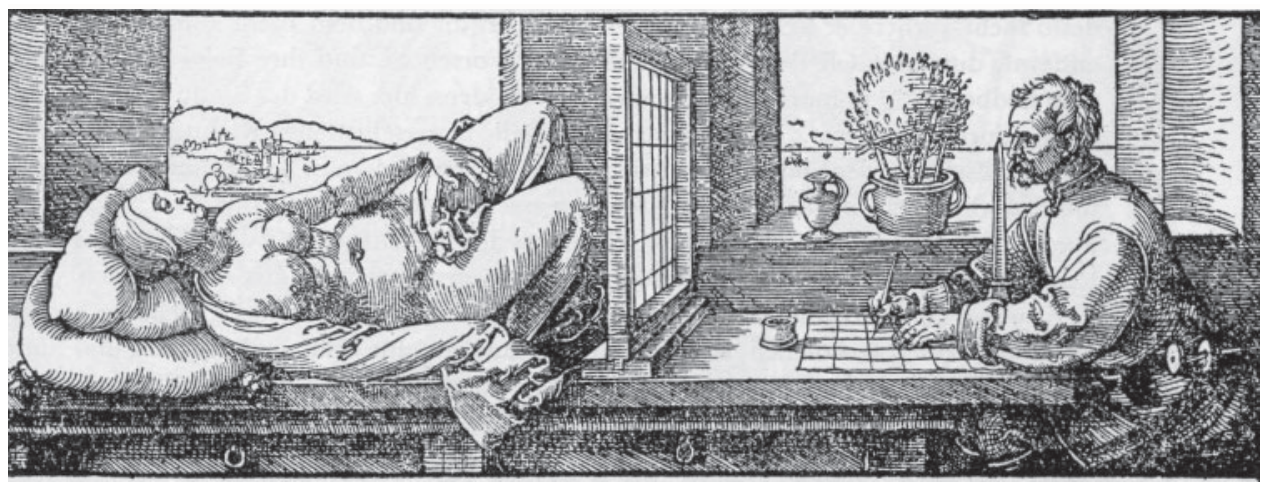

\section{An dem, was rund ist, zeigt sich der Meister}

Damals, in den fünfziger Jahren, lernten wir zwei neue Worte. "Sputnik» und "Atombusen". Beide stellten wir uns rund und sehr gewaltig vor. Der eine brachte Ost und West durcheinander, der andere die pubertierende Republik. So war das damals. Später, als die Weltraumfahrzeuge größer wurden und die Körbchen kleiner, blieben immer noch die Worte, die Vorstellungen, die Bilder, rund und sehr gewaltig. Bilder kann man nicht löschen wie die Geschichten, die zu den Bildern gehören. Bilder bestimmen unser Verhältnis zur Welt. Alle Welt ist in Bildern ausgelegt, in Bildern von Dingen, von Menschen, von Körpern.

Tausendfach sind die Körper mit Bildern umstellt. Sie liegen ihnen dichter an als alle Kostüme und Kostümierungen, in denen sie sich zeigen und verbergen. Bevor wir den Körper berühren, bevor wir ihn in Händen halten, haben wir ihn schon gesehen - seine Bilder, die ihn kleiden in tausend Schichten.

Bilder des Körpers entstehen im Atelier. Dort liegt die unbekleidete Frau auf den Kissen und rührt sich nicht. Und das Gitter, das Albrecht Dürer zwischen Maler

Zum Autor: Hans-Joachim Müller

- Studium der Philosophie und

Kunstgeschichte in Freiburg i. Br.

- langjähriger Mitarbeiter im

Feuilleton der ZEIT

- zuletzt Feuilletonchef und

Mitglied der Redaktionsleitung

der Basler Zeitung

- lebt heute als freier Autor

(FAZ, ZEIT, NZZ, art-Magazin) in

Freiburg und in Süditalien. und Modell stellt, ist nicht dazu da, um die beiden auf schicklichen Abstand zu halten. Aufgabe ist, die Körpermaße Quadrant um Quadrant zu protokollieren, dafür ist das Gitter gut. Für die Landschaft draußen vor dem Fenster ist beim Körpermaßenprotokoll kein Blick. Die Botschaft ist deutlich: Künstler, träum' nicht, vor dir liegt Arbeit.

Nun ist es ja nicht eigentlich Arbeit, die vor dem Künstler liegt, sondern eine unbekleidete Frau. Und ganz so selbstverständlich ist es vielleicht doch nicht, dass vor einem, Maler hin oder her, eine unbekleidete Frau auf dem Tisch liegt. Und so wie die unbekleidete Frau auf dem Tisch liegt, ist es schon gar nicht selbstverständlich. Ihr Liegen, ihr Unbekleidetsein ist Inszenierung. Und zur Inszenierung gehört auch die Tarnung des Zeichners hinter seinen Gitterrahmen, die mathematische Strenge, mit der er seinen Perspektographen vor Augen und Nase platziert hat und so tut, als gehe es in diesem Augenblick um nichts anderes als um Fluchtlinien. Inszenierung ist, wie die Aussicht nach draußen und die Ansicht drinnen versperrt bleiben, wie alle gefährlichen Phantasien in der Gelassenheit des Zeichenstifts aufgehoben scheinen.

Nacktheit. Worauf schaut der Maler? Auf sein Blatt, auf seine Leinwand. Hin und wieder gestattet er sich einen Augenaufschlag - studienhalber. Einen Diagnoseblick aufs Modell, das seine Dienstleistung so routiniert erbringt wie das Personal in Küche und Kinderzimmer. Henri Matisse hat im Atelier gerne einen weißen Mantel übergezogen. Vielleicht um die klinische Atmosphäre herzustellen, die die kunstgerechte Verletzung der Intimität überhaupt erträglich macht. Die runden Linien sind dem Malerarzt bei der Visite gelungen wie keinem mehr im 20. Jahrhundert. Rücken, Gesäß, Brüste. Ein Stücklein zitterfreie Gerade kriegt noch jeder hin. An dem, was rund ist, zeigt sich der Meister. An Rücken, Gesäßen, Brüsten haben fast immer männliche Zeichenhände ihre Zitterfreiheit erprobt. Malerin und Modell sind nicht die Regel. Wie sähe es in den Museen, in unseren Köpfen aus, wenn die Bilder von Künstlerinnen gemalt worden wären? Es ist gar nicht zu ermessen, wieviel die Körperimago der 
maskulinen Bildgeschichte verdankt. Was als erotische Sensation zu gelten hat, ist nicht einfach gegeben wie die Zahl Pi, die man zur Kreisberechnung braucht. Es ist kultureller Herkunft, vermittelt durch eine Bilderproduktion, an der die Malerärztinnen jedenfalls nicht korrigierend beteiligt waren.

Natürlich könnte man einwenden: Was hätte auch der nackte Mann zu bieten? Die Muskeln des Herakles. Den Schmerzensleib des Gekreuzigten. Die Pfeile im Edelfeisch des heiligen Sebastian. Adam und die Freudlosigkeit des Prototyps. Nie hat seine paradiesische Adoleszenz die Maler zu gefährlichen Phantasien verführt. Und Narziss, der am Wasser hockt und über sein schönes Spiegelbild greint, erscheint - rundkörperlich gesehen - ja nun auch nicht gerade als klassisches Begehrensmotiv. Es hat so gesehen schon seine Richtigkeit, wenn die Zuständigkeit für die Liebe bei Frau Venus ressortiert und nicht bei Herrn Apoll. Mit fehlendem, defizitärem oder feigenblattgedeckeltem Gemächt' mag einer Gott des Lichtes, der sittlichen Ordnung und des schönen Maßes sein, zu mehr hat er nicht das Zeug.

Ohnehin gehören Geschlechtsteile verhüllt. Sie sind ein bisschen peinlich, und das hat die Geschichte der Bilder immer so empfunden und hat sich bis auf grobe Verstöße an die gnädige Verdeckung und Versteckung gehalten. Umso mehr Darstellungswürde hat die weibliche Brust. Sie ist nicht peinlich. Sie ist rund. Eine Herausforderung für Bildermacher - mit und ohne weiße Mäntel. In ihren Bildern ist der Körper der Frau vollends öffentlich geworden. Und immer wird weibliche Intimität begleitet von der Zurschaustellung von Intimität, immer gehört zur bekleideten Brust ein Bild, das sie unbekleidet zeigt. Selbst Scham, also der Versuch, den Körper durch ein starkes Gefühlssignal zu reprivatisieren, ist von den öffentlichen Bildern der Scham nicht zu trennen.
Es ist diese überfüllte Bildergeschichte des Körpers, des weiblichen Körpers, vor dem es keinen wirksamen Kleiderschutz gibt, keinen verlässlichen Rückzug ins unverfügbar Eigene. Kleider verbergen so wenig, wie der weiße Mantel des Malers vor zuviel Nähe bewahrt. Auf eine unumkehrbare Weise ist der Körper der Frau bildöffentlich geworden. Dass Bilder fiktive Wirklichkeit, nicht die Wirklichkeit selber sind, tröstet nicht recht. Wenn es um den Körper geht, um sein Aussehen, Auftreten, Erscheinen, Verhalten sind die Vorstellungen von ihm, die öffentlich verhandelten Bilder, gerade so bestimmend wie die genetischen Programme in ihren Zelleinschlüssen. Und die strenge Trennung von rundem Gewebe und runder Linie ist selber schon fiktional.

Von Zeuxis, dem antiken Maler, wird berichtet, dass er nicht wirklich verwundert darüber gewesen sei, als Vögel auf seine Trauben zugeflogen kamen, die er mit soviel naturidentischen Aromastoffen gemalt hatte. Verwundert nur soll er gewesen sein, wie die Vögel keinerlei Angst vor dem Trauben haltenden Knaben gezeigt hätten, auf den er doch gerade soviel Akkuratesse verwandt habe. Wohl ist es mit dem Knaben wie mit den männlichen Aktbildern: Von ihm, von ihnen ist nichts zu befürchten. Sie sind harmlos, als harmlose Bilder viel leichter zu erkennen als die Trauben - und die Brüste, von denen ein starker Reiz ausgeht. Und starker Reiz bedeutet Erkenntnis trübende Verführung.

In Wahrheit war der Maler auch ein bisschen beleidigt über die partielle Verkennung seines Meisterwerks. Und wer ihm nun mit der eingeschränkten ornithologischen Einsichtsfähigkeit kam, der hat sich nur eine Abfuhr geholt. Wenn der Maler klug war, hat er ein paar Vögel dazu gemalt und sein Bild der Erfahrung angepasst. So wie uns bald einmal die Erfahrung lehrte, dass es der Sputnik nie zur Serienreife bringen wird und der Atombusen doch nicht als Regelfall zu gelten hat.

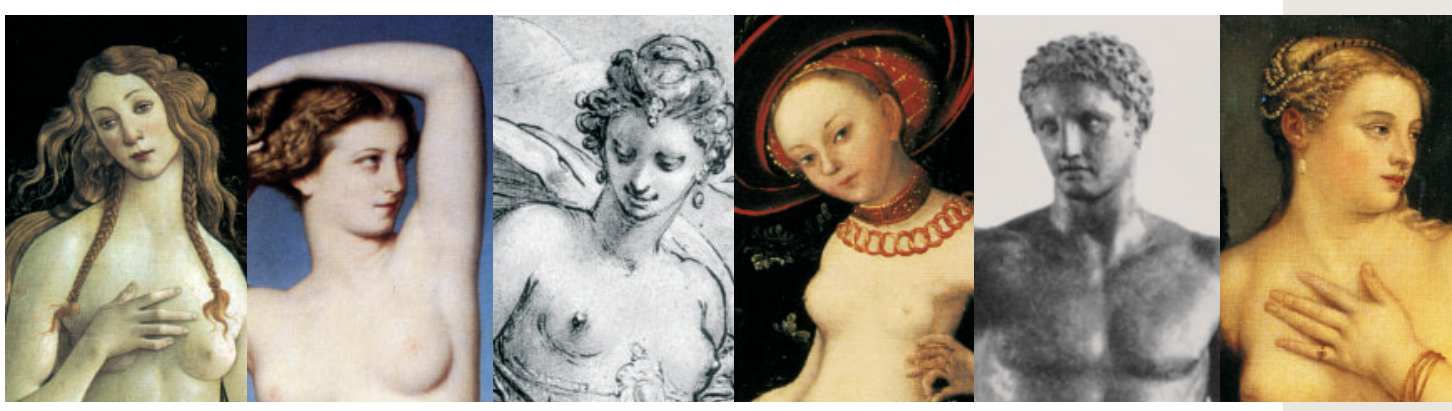

